\title{
SISTEM KEPENGARANGAN DALAM SERAT-SERAT WULANG PAKUBUWONO IX
}

\author{
Sri Harti Widyastuti \\ Fakultas Bahasa dan Seni Universitas Negeri Yogyakarta \\ email: sriharti@uny.ac.id
}

\begin{abstract}
Abstrak
Penelitian ini bertujuan mendeskripsikan sistem kepengarangan dalam serat-serat wulang Pakubuwono (PB) IX. Data penelitian berupa kata dan kalimat yang menunjukkan sistem kepengarangan dalam serat-serat wulang PB IX. Pengumpulan data dengan metode filologi modern. Analisis data menggunakan metode deskriptif dengan penerapan teori asal-usul teks. Hasil penelitian sebagai berikut. Pertama, terdapat peran PB IX sebagai pengarang dan penulis atau ingkang anganggit dan ingkang anyerat dalam serat-serat wulang PB IX. Peran ini dibantu oleh penulis kerajaan untuk mengikat karyanya. Peran tersebut ditunjukkan penggunaan gaya tuturan dengan penyebutan kata adikku, guruku Ngabdul Kahar, guruningwang, trahingwang, anakku, woting tyasingsun, dan sutengsun. Kedua, terdapat peran PB IX sebagai pengayom. Peran ini tampak pada manggala dan kolofon teks yang diikuti bentuk sengkalan. Yang memiliki peran pengayom biasanya adalah seorang pujangga kerajaan atau penulis kerajaan yang cukup ternama. Dalam serat-serat wulang PB IX ini muncul pengarang dan penulis, yaitu Nyai Tumenggung Adisara.
\end{abstract}

Kata kunci: serat wulang, Pakubuwono IX, pengayom, filologi modern

\section{THE AUTHORSHIP SYSTEM IN SERAT-SERAT WULANG BY PAKUBUWONO IX}

\begin{abstract}
This study aims to describe the authorship system in serat-serat wulang (teaching works) by Pakubuwono (PB)IX. The data were in the form of words and sentences describing the authorship system in serat-serat wulang by PB IX. They were collected using the modern philology method. The data analysis used the descriptive method by applying theories on the origins of texts. The results are as follows. First, there are roles of PB IX as the author (ingkang anganggit) and the writer (ingkang anyerat) in serat-serat wulang PB IX. These roles are assisted by the court author in order to bind the works. The roles are shown in the use of some special terms such as adikku, guruku Ngabdul Kahar, guruningwang, trahingsun, anakku, woting tyasingsun, and sutengsun. Second, there is a role of PB IX as pengayom (patron). This is shown in manggala and the text colophon followed by a form of sengkalan (chronogram). A patron is usually a famous court poet or writer. In serat-serat wulang by PB IX, there is an author or writer, namely Nyai Tumenggung Adisara.
\end{abstract}

Keywords: serat-serat wulang, Pakubuwono IX, patron, modern philology 


\section{PENDAHULUAN}

Sastra wulang, piwulang, atau niti adalah genre karya sastra yang sangat terkenal dalam sastra Jawa. Karya-karya itu tumbuh subur pada periode sastra Jawa Baru, yaitu abad XIV sampai dengan abad XIX. Seratserat wulang karya Pakubuwono IX (selanjutnya disingkat PB IX) disusun untuk memberi ajaran dan nasihat kepada para putra-putri raja, para kerabat, abdi dalem yang akan mengabdikan hidupnya untuk kerajaan. Namun demikian, ajaran-ajaran tersebut dapat pula dibaca dan diimplementasikan untuk rakyat secara umum.

PB IX adalah seorang raja yang mempunyai ide-ide cemerlang berhubungan dengan visi pemerintahannya yang ingin menciptakan tertib dunia dan tertib spiritual. Oleh karena itu, PB IX banyak melakukan strategi dan merumuskan konsepkonsep untuk kemajuan dan kemakmuran pada masa pemerintahannya. Selain itu, PB IX juga mempunyai perhatian sangat besar pada perkembangan seni dan sastra. Keinginan untuk menciptakan tertib dunia, yaitu tertib sosial dan masyarakat disampaikan dalam karya-karyanya.

Pada masanya, PB IX banyak menghasilkan karya-karya sastra. Hasil karya sastra tersebut sering disebut anggitan. Hal tersebut sesuai dengan teori asal-usul teks yang menyatakan bahwa terjadinya teks yang pertama, adalah kemungkinan teks terjadi dari yang aslinya hanya ada dalam ingatan pengarang atau pengelola cerita, turun-temurun terjadi secara terpisah melalui dikte. Kedua, teks asli adalah teks tertulis yang merupakan kerangka yang masih memungkinkan atau memerlukan kebebasan untuk dikembangkan. Kemungkinan aslinya disalin begitu saja dengan tambahan seperlunya atau dikembangkan dengan maksimal. Ketiga, teks asli merupakan teks karya pengarang yang tidak mengizinkan kebebasan penyalin (BarorohBaried, 1985: 57). Terkait dengan pendapat di atas, maka kemungkinan besar pada abad ke-16 sampai abad ke-17 kedudukan penulis kerajaan atau carik yang kemudian menjadi empu atau bahkan pujangga merupakan abdi dalem keraton. Seorang raja dapat memerintahkan membuat karya sastra dengan cara mendiktekan pokok-pokok persoalan yang harus dimasukan dalam karya sastranya. Seorang raja mungkin membuat kerangka cerita untuk dikembangkan oleh pujangganya atau bahkan dapat pula seorang raja membuat sendiri karya sastra. Cara proses menulis yang dilakukan seperti halnya kejadian katarsis. Pada penciptaan teks, nama pemrakarsa, atasan, atau raja ditulis di bagian depan teks (Saktimulya, 2016: 12).

Kehidupan sastra budaya pada waktu itu dikelola dengan baik oleh kekuasaan dan pemerintahan (Behrend, 1993: 414). Penulis atau carik mendapat kedudukan dan fasilitas yang sangat baik. Ciri kesusastraan Jawa Klasik adalah anonim, yaitu tidak menyebutkan nama pengarang, karena semua jiwa dan raga rakyat adalah milik dan dipersembahkan untuk raja sesuai cultus dewa raja, yaitu kepercayaan bahwa raja adalah penjelmaan dewa di dunia. Raja adalah penguasa mutlak. Segala sesuatu yang berkembang di bumi adalah milik raja (Wahyono, 2004: 2).

Dalam kajian tentang pengarang dan kepengarangan terhadap naskah-naskah Surakarta abad ke-18 dan 19, menunjukkan adanya kekaburan (Margana, 2004: 22). Dalam naskah Jawa, istilah panyerat 
yang berarti penulis atau writer tidak selalu identik dengan istilah author. Istilah ingkang anyerat belum tentu juga sama dengan ingkang nganggit (yang mengarang). Ingkang anyerat seringkali hanyalah orang yang menuliskan naskah, sedangkan pengarangnya mungkin orang lain (Margana, 2004: 24). Sementara itu, dalam naskah Jawa muncul pula istilah ingkang angiket (yang mengumpulkan), ingkang akarya sastra (yang mengerjakan teks), ingkang anedhak (yang menyalin) (Florida, 2000).

Selanjutnya, Margana (2004: 24-25) menegaskan bahwa dalam dunia naskah Jawa dibedakan istilah pengarang, penulis, penyalin atau yang mengumpulkan karangan. Namun, istilah ingkang anganggit yang lebih dekat dengan identifikasi pengarang jarang ditentukan. Tampaknya presentasi dan representasi naskah Jawa bukanlah sebuah kerja individual tetapi sering merupakan sebuah kerja kolektif. Sesuai dengan pendapat tersebut, maka kepengarangan PB IX merupakan sosok ingkang anganggit yang kemudian dikerjakan oleh penulis istana. Demikian pula, dapat dianalogikan bahwa serat-serat wulang sebagai karya yang teksnya berupa ide dan pikiran raja yang kemudian diteruskan oleh penulis keraton atau oleh pujangga.

Selain hal itu, kemungkinan PB IX membuat kerangka berpikir yang selanjutnya diteruskan oleh penulis keraton atau pujangga. Kemungkinan lain, PB IX menulis sendiri teks yang sesuai dengan keinginannya. Pada periode tertentu diteruskan oleh penulis keraton atau pujangga. Hal itu seperti terjadi pada pembuatan karya-karya seperti Serat Centhini yang mulai ditulis pada bulan Januari tahun 1814, selesai tahun 1823 dengan tim penulis yang dipimpin dan diprakarsai oleh Adipati Anom Amangkunegara III, putra mahkota Kerajaan Surakarta yang kemudian menjadi raja dengan gelar Sunan Pakubuwana V. Adapun anggota tim penulisan tersebut adalah Kyai Ngabehi Ranggasutrasna, Kyai Ngabehi Yasadipura II, dan Kyai Ngabehi Sastradipura. Ketiga anggota tim merupakan pegawai kepujanggaan di Kerajaan Surakarta (Marsono, 2015: 3).

Berdasarkan pendapat di atas, maka pengertian karya dalam sastra Jawa Klasik dengan karya sastra Jawa Modern berbeda. Pada karya sastra Jawa Modern, pengertian karya adalah hasil tulisan yang dinilai dari ide, penulisan sampai menjadi sebuah karya yang siap disampaikan kepada pembaca. Sementara, pengertian karya pada masa Jawa Klasik bisa merupakan karangan seseorang yang langsung ditulisnya, dapat pula yang menunjukkan sebuah karya adalah ide dan kerangka karangan yang disampaikan raja yang diteruskan penulis keraton.

Penulis bertugas mengembangkan ide dan kerangka pikir tersebut. Penulis keraton adalah pegawai yang diangkat khusus untuk menulis semua hal terkait dengan kebutuhan kerajaan. Oleh karena itu, seorang penulis merupakan pegawai yang tugasnya memang menulis, sehingga nama raja yang memerintahkan untuk membuat teks memang harus dituliskan. Makalah ini diambil dari penelitian yang berjudul "Konsep Kekuasaan Islam Jawa yang Terdapat Pada Serat-serat Wulang PB IX dan Konstelasinya dalam Sejarah Sastra Jawa".

Sumber data penelitian ini adalah 8 naskah. Adapun 8 naskah tersebut yaitu:

a. Naskah dengan kode 14235 (47 ha) atau $336 \mathrm{Ca}$ berjudul Wulang Dalem 
Ingkang Sinuhun Pakubuwana IX, dalam penelitian ini diberi kode A.

b. Naskah dengan kode 444 Ca 14243 (444 Ha) sama dengan naskah dengan kode 702 berjudul Wulang Dalem Sampeyan Dalem Ingkang Sinuhun Kangjeng Susuhan Pakubuwana Ingkang Kaping IX, dalam penelitian ini diberi kode $B$.

c. Teks yang merupakan transliterasi naskah Wulang Dalem Warni-Warni. Hasil transliterasi diberi judul Wulang Dalem Warni-Warni PB IX yang diterbitkan oleh Balai Penelitian Bahasa Yogyakarta tahun 1983, dalam penelitian ini diberi kode C.

d. Naskah dengan kode Pw 177 dengan judul Piwulang Dalem PB IX merupakan kumpulan dari berbagai teks yang disimpan di Fakultas Sastra Universitas Indonesia (Behrend, 1997: 772), dalam penelitian ini diberi kode $\mathrm{D}$.

e. Naskah dengan kode P 27 PB A. 59 berjudul Wulang Dalem Pakubuwana IX. Naskah terdapat dalam kumpulan naskah berjudul Serat Piwulang WarniWarni, dalam penelitian ini diberi kode E.

f. Naskah dengan kode P 28, SK 20 berjudul Kempalan Serat Warni-Warni (Behrend, 1997: 462), dalam penelitian ini diberi kode $\mathrm{F}$.

g. Naskah dengan kode Pi 28 atau 58575 berjudul Serat Piwulang Warni-Warni I yang tersimpan di Perpustakaan Pura Pakualaman Yogyakarta, dalam penelitian ini diberi kode $\mathrm{G}$.

h. Naskah dengan kode Pi. 8 berjudul $W u$ lang Dalem Ingkang Sinuhun Kanjeng Susuhunan ing Surakarta kaping IX yang merupakan teks ke-19 dari kumpulan naskah Kempalan Serat Piwulang disimpan di Perpustakaan Pura Pakualaman Yogyakarta. Naskah Pi 8 dalam katalog Descriptive Catalogue Of The Javanese Manuscripts and Printed Books In The Main Libraries Of Surakarta and Yogyakarta ditulis dengan kode 54125 (0032) (Girardet, 1983: 741), dalam penelitian ini diberi kode $\mathrm{H}$.

\section{METODE}

Metode yang digunakan adalah metode penelitian filologi modern dan deskriptif. Metode filologi modern digunakan untuk terbaca. Selanjutnya, metode deskriptif digunakan untuk mengolah data deskriptif berupa kata, kalimat, dan paragraf. Data yang terkumpul dari delapan naskah dan teks dianalisis dengan menyimak dan membaca secara cermat sesuai dengan teori kepengarangan.

Sementara metode filologi modern digunakan melalui langkah-langkah penelitian, yaitu inventarisasi naskah, deskripsi naskah, transliterasi naskah, dan terjemahan. Transliterasi naskah yang digunakan adalah mentransliterasi standar, yaitu mentransliterasi dari huruf Jawa ke huruf Latin dengan melakukan pembetulan-pembetulan sesuai dengan ejaan yang berlaku tanpa meninggalkan konteks (Darusuprapta, 1984: 2).

Sedangkan terjemahan yang digunakan adalah terjemahan dari bahasa Jawa Baru ke bahasa Indonesia. Adapun metode terjemahan yang dilakukan adalah terjemahan harfiah, terjemahan isi, dan terjemahan bebas. Terjemahan harfiah dilakukan sebagai dasar untuk melakukan terjemahan isi agar supaya makna teks dapat dite- 
rangkan. Terjemahan isi adalah penggantian bahasa sumber ke bahasa sasaran. Berdasarkan isi atau maknanya, apabila kedua metode tersebut masih belum dapat digunakan untuk menerangkan makna secara jelas, maka digunakan terjemahan bebas, yaitu mengganti makna secara bebas.

\section{HASIL DAN PEMBAHASAN PB IX sebagai Pengarang dan Penulis}

Berdasarkan penelitian terhadap teksteks serat-serat wulang PB IX, maka didapatkan hasil penelitian yang menunjukkan bahwa PB IX menulis dan mengarang karya yang sangat banyak. Hal tersebut karena PB IX menulis karya sastra dipengaruhi oleh kehidupan sosial, ekonomi, politik, dan proses estetisnya (Dharwadker, 2003: 200). Menurut Margana, istilah ingkang nganggit atau yang mengarang belum tentu sama dengan ingkang anyerat atau yang menulis. Ingkang anyerat adalah orang yang menuliskan naskah itu, sedangkan pengarangnya mungkin orang lain. Ada pula istilah ingkang angiket atau yang mengumpulkan, yaitu orang yang mengumpulkan teks-teks dalam bentuk kumpulan teks (Margana, 2003: 24).

Disamping fenomena tersebut, teks-teks kadang-kadang merupakan hasil dari pembacaan kembali teks sebelumnya yang perlu penelitian lebih lanjut untuk memilah teks yang ditransformasi dan teks transformasi. Hal itu wajar, seperti yang disebutkan oleh Skulj yang menyatakan bahwa fakta literatur tertulis dalam jaringan fenomenologi dan determinasi intertekstual yang saling terkait sehingga menggambarkan karakter permanen mobilitas, ketidakstabilan, dan reformulasi inventif matriks lisan teks sastra yang harus ditafsirkan kembali melalui penyebaran sastra yang selalu baru. Selanjutnya, untuk memudahkan pembacaan, di bawah ini tabel data PB IX sebagai pengarang dan penulis.

\section{Tabel 17. Peran PB IX sebagai Pengarang dan Penulis}

\begin{tabular}{|c|c|c|c|c|}
\hline No. & Judul Karya & Indikator Karya & Terjemahan & Varian \\
\hline 1. & $\begin{array}{l}\text { Serat Wulang } \\
\text { Dalem Kaping IX }\end{array}$ & $\begin{array}{l}\text { Sêdhêngé maksih taruna/ } \\
\text { dhuh woting tyasingsun } \\
\text { yayi/ mangajiya ing } \\
\text { kawignyan/ } \\
\text { Luwiha saking waking sun/ } \\
\text { prawira prakosa lantip/ } \\
\text { dhuh mulané ariningwang/ } \\
\text { Inggih punika anggitan } \\
\text { dalêm/ Sampéyan Dalêm } \\
\text { Ingkang Sinuhun Kangjêng } \\
\text { Susuhunan Pakubuwana } \\
\text { Ingkang Jumênêng Kaping } \\
\text { 9// }\end{array}$ & $\begin{array}{l}\text { Ketika waktu masih } \\
\text { muda/ aduh Adikku } \\
\text { kekasih hatiku/ belajarlah } \\
\text { tentang kepandaian/ } \\
\text { Lebih baiklah dariku/ } \\
\text { perwira perkasa yang } \\
\text { pintar/ aduh, maka dari } \\
\text { itu Adikku/ } \\
\text { yaitu karya/ Sampeyan } \\
\text { Dalem ingkang Sinuhun } \\
\text { Kangjeng Susuhunan } \\
\text { Pakubuwana ingkang } \\
\text { Jumeneng Kaping 9// }\end{array}$ & $\begin{array}{l}\text { Teks A, p.2, b.1 } \\
\text { Teks C, p. } 2, \text { b. } 1 \\
\text { Teks D, p. } 1, \text { b. } 1 \\
\text { Teks A, p. } 3, \text { b. } 4 \\
\text { Teks C, p. } 3, \text { b. } 4 \\
\text { Teks D, p. } 2, \text { b.4 }\end{array}$ \\
\hline
\end{tabular}




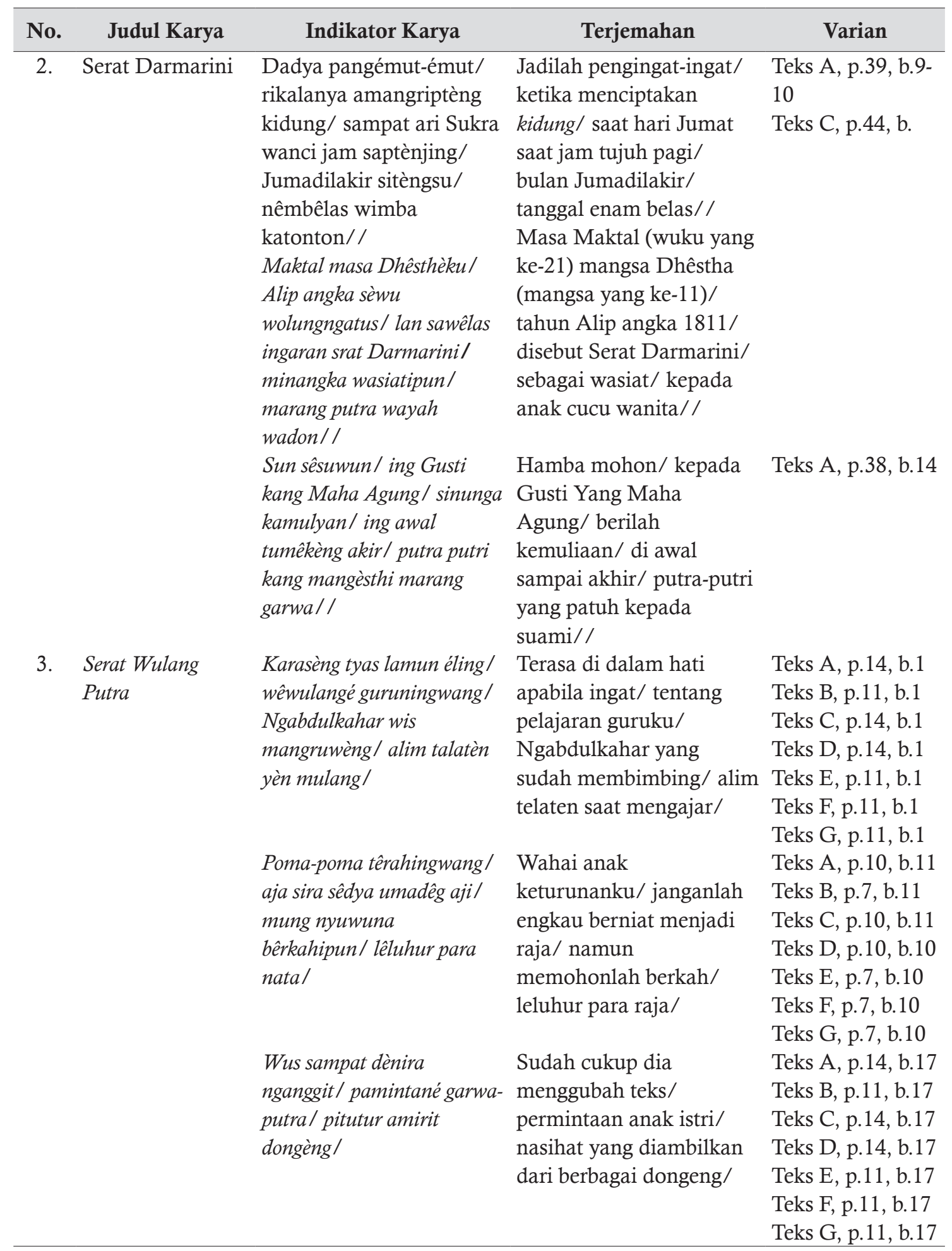

18 | LITERA Volume 17, Nomor 1, Maret 2018 


\begin{tabular}{|c|c|c|c|c|}
\hline No. & Judul Karya & Indikator Karya & Terjemahan & Varian \\
\hline 4. & Serat Jayeng Sastra & $\begin{array}{l}\text { Palastrèng cinitra wus/ } \\
\text { kagungan dalêm ingkang } \\
\text { Sinuhun/ Pakubuwana } \\
\text { kaping Sanga marêngi/ } \\
\text { linuri-luri kang luhur/ } \\
\text { Surakarta angadhaton// }\end{array}$ & $\begin{array}{l}\text { Sudah larut di dalam } \\
\text { gambaran/ kepunyaan } \\
\text { Dalêm Ingkang Sinuhun/ } \\
\text { Pakubuwana ke-9/ dalam } \\
\text { rangka memberi nasihat } \\
\text { yang luhur/ yang } \\
\text { berkedudukan di } \\
\text { Surakarta// }\end{array}$ & $\begin{array}{l}\text { Teks B, p.18, b.18 } \\
\text { Teks D, p.21, b.18 }\end{array}$ \\
\hline \multirow[t]{3}{*}{5.} & $\begin{array}{l}\text { Serat Gandrung } \\
\text { Turida }\end{array}$ & $\begin{array}{l}\text { Si kulup ingkang kantun/ } \\
\text { lêstariya mêngku praja di/ }\end{array}$ & $\begin{array}{l}\text { Si Buyung anakku yang } \\
\text { ditinggalkan/ lestarilah } \\
\text { dalam memangku } \\
\text { kerajaan yang agung/ }\end{array}$ & $\begin{array}{l}\text { Teks A, p. } 41, \text { b. } 2 \\
\text { Teks B, p. } 42, \text { b. } 2 \\
\text { Teks C, p. } 46, \text { b. } 2 \\
\text { Teks D, p. } 43, \text { b.2 }\end{array}$ \\
\hline & & $\begin{array}{l}\text { Dhuh woting tyas ingsun } \\
\text { wong akuning / ingsun nora } \\
\text { nusul mring dêlahan / nêng } \\
\text { jagat akèh gawéné/ prêlu } \\
\text { ngrêksa nak-putu/lan } \\
\text { mênungsa isining nagri/ }\end{array}$ & $\begin{array}{l}\text { Wahai kekasih hatiku/ } \\
\text { hamba mengatakan } \\
\text { hamba tidak akan } \\
\text { menyusul di akhirat/ di } \\
\text { dunia banyak pekerjaan/ } \\
\text { untuk menjaga anak } \\
\text { cucu/ dan manusia seisi } \\
\text { negara/ }\end{array}$ & $\begin{array}{l}\text { Teks A, p. } 41, \text { b. } 3 \\
\text { Teks B, p. } 42, \text { b. } 3 \\
\text { Teks C, p. } 46, \text { b. } 3 \\
\text { Teks D, p. } 43, \text { b. } 3\end{array}$ \\
\hline & & $\begin{array}{l}\text { Narimaa wakingsun iki/ } \\
\text { éwuh lamun Naréndra/ } \\
\text { tanpa timbang iku/ dhuh } \\
\text { Gusti sira mangsita/ sapa } \\
\text { ingkang winahyu sagung } \\
\text { pawèstri/ dadi } \\
\text { timbanganing wang// }\end{array}$ & $\begin{array}{l}\text { Pasrahlah hambamu ini/ } \\
\text { namun tidak baik seorang } \\
\text { raja/ tanpa permaisuri/ } \\
\text { wahai Tuhan berilah } \\
\text { perlambang di antara } \\
\text { seluruh wanita siapa yang } \\
\text { diberi wahyu/ menjadi } \\
\text { permaisuri hamba// }\end{array}$ & $\begin{array}{l}\text { Teks A, p.41, b. } 8 \\
\text { Teks B, p. } 42, \text { b. } 8 \\
\text { Teks C, p. } 46, \text { b. } 8 \\
\text { Teks D, p.43, b. }\end{array}$ \\
\hline \multirow[t]{2}{*}{6.} & Serat Wararatna & $\begin{array}{l}\text { Dhuh sutèngsun / rungunên } \\
\text { manira wuruk / kabèh kang } \\
\text { tinitah / éndyah rèhning sira } \\
\text { èstri/ mung sun kaya sanépa } \\
\text { wêwulangingwang// }\end{array}$ & $\begin{array}{l}\text { Wahai anakku/ } \\
\text { dengarkan ajaranku/ } \\
\text { semua yang ditakdirkan/ } \\
\text { hanya engkau yang } \\
\text { dipilih sebagai contoh } \\
\text { wejanganku ini/ karena } \\
\text { engkau seorang wanita// }\end{array}$ & $\begin{array}{l}\text { Teks A, p. } 40, \text { b. } 8 \\
\text { Teks C, p. } 45, \text { b. } 8\end{array}$ \\
\hline & & $\begin{array}{l}\text { Cêkakipun/ supaya énggal } \\
\text { dhinapur/ nini } \\
\text { putraningwang/ èstokêna } \\
\text { basa gati/ basa wadon/ iku } \\
\text { wadi têgêsira// }\end{array}$ & $\begin{array}{l}\text { Singkatnya/ agar } \\
\text { gubahan ini segera } \\
\text { selesai/ wahai putriku/ } \\
\text { camkan kata-kata ini/ } \\
\text { bahasa wanita/ itu } \\
\text { artinya rahasia// }\end{array}$ & $\begin{array}{l}\text { Teks A, p. } 40, \text { b. } 9 \\
\text { Teks C, p. } 45, \text { b. } 9\end{array}$ \\
\hline
\end{tabular}




\begin{tabular}{llll}
\hline No. Judul Karya & \multicolumn{1}{c}{ Indikator Karya } & \multicolumn{1}{c}{ Terjemahan } & \multicolumn{1}{c}{ Varian } \\
\hline & Dhuh sutèngsun/ iyêku & Wahai anakku/ & Teks A, p.40, b.16 \\
sanêpanipun/ sasmita kang & demikianlah ibaratnya/ & Teks C, p.45, b.9 \\
nyata/ ngong cêkak & perlambang yang nyata/ & \\
wêwulang iki/ dèn èstokna & nasihat pendekku ini/ & \\
& rasaning srat Wararatna/ & laksanakan isi dari Serat & \\
& Wararatna// & \\
\hline
\end{tabular}

Dalam tabel terlihat peran PB IX sebagai pengarang dan penulis. Hal itu tampak pada gaya tuturan dalam teks. Peran PB IX sebagai ingkang anganggit dan ingkang anyerat juga tampak pada tulisan seseorang yang disebut ingkang angiket. Peran PB IX sebagai pengarang dan penulis atau ingkang anganggit dan ingkang anyerat dapat diketahui dari penyebutan terhadap sosok seperti adikku, guruku Ngabdul Kahar, guruningwang atau guruku, trahingwang atau keturunanku, anakku, woting tyasingsun atau kekasih hatiku, sutengsun atau anakku.

Disebutkan dalam teks di atas bahwa PB IX menyebut adik-adiknya agar belajar ilmu kepandaian termasuk belajar tentang perilaku wanita, supaya tidak mengecewakan hati, demikian pula agar patuh pada perintah atasan. Penanda peran $\mathrm{PB}$ IX sebagai pengarang dan penulis pada teks A, terdapat pada pupuh 3, bait 4-5.

Luwiha saking waking sun/ prawira prakosa lantip/dhuh mulanéariningwang/ ywa pêgat rahina wêngi/ nênêdhaa mring Ywang Suksma/ arjaa kang badhé mijil//

Nora gampang dhuh riningsun/ gêgadhangan narapati/ kudu pininta lan tapa/ sakuwasanira yayi/ tamtuning para naréndra / daliling Ywang Mahasuci//

Artinya:

Lebih baiklah dariku/ perwira perkasa yang pintar/ aduh, maka dari itu
Adikku/ jangan berhenti siang malam/ berdoalah kepada Hyang Sukma/ semoga selamat (putra) yang akan lahir//

Tidak mudah aduh Adikku/ harapan raja (agar dapat terwujud)/ harus berdoa dan bertapa/ sekuatmu dik/ tentunya para raja/ menjadi dalil dari Sang Mahasuci//

Dalam bait-bait di atas disebutkan bahwa PB IX menasihati permaisuri agar tidak berhenti berdoa siang malam agar putranya dapat lahir dengan selamat dan harapan calon raja harus diperjuangkan dengan berdoa dan bertapa. Dalam teks tersebut terdapat kata adikku.

Dalam Serat Wulang PB IX pada bagian teks yang berjudul Serat Wulang Dalem $P B$ $I X$ yang terdapat pada kumpulan naskah A, B, C, D, E, F, dan G tampak peran PB IX sebagai pengarang dan penulis. Namun demikian, teks dari PB IX dimungkinkan masih ditata kembali oleh seorang penulis keraton. Hal tersebut tampak pada tulisan di bagian manggala yang menyebut ajaran agung Susuhunan yang ke-IX di Surakarta yang bertahta di Surakarta seperti pada kutipan berikut:

Wiyata di/ anggit Dalêm/ Jêng Srinata / / Kang Jumênêng ping Sanga Surakarta dil myang panyidhikara/ Garbini Dalêm sang Sori/ Jêng Ratu Pakubuwana// (teks A pupuh 1, bait 1-2) 
Artinya:

Ajaran agung/ karya/ Susuhunan// Yang ke-9 di Surakarta/ yang bertahta di Surakarta dengan doa/ dari permaisuri yang sedang hamil/ yaitu Kanjeng Ratu Pakubuwana//

Kutipan penanda penguat bahwa karya sastra ini adalah karya PB IX terdapat setelah pupuh 3 bagian prosa yang menyatakan bahwa serat sudah tamat ditulis karya Dalem Sampeyan Dalem Ingkang Sinuwun Kangjeng Susuhunan Pakubuwana Jumeneng Kaping 9, seperti kutipan di bawah ini:

Punika katranganipun sêrat kasêbut ing kaca angka: 1115: dumugi kaca angka: 1120: wau sampun tamat/ inggih punika anggitan dalêm/Sampéyan Dalêm Ingkang Sinuhun Kangjêng Susuhunan Pakubuwana Ingkang Jumênêng Kaping 9//

\section{Artinya:}

Ini keterangan serat tersebut di halaman nomor 1115 sampai halaman nomor 1120 tadi sudah tamat/ yaitu karya Dalem/ Sampeyan Dalem ingkang Sinuhun Kangjeng Susuhunan Pakubuwana ingkang Jumeneng Kaping $9 / /$

Penanda PB IX sebagai seorang pengarang dan penulis juga tampak pada Serat Wulang Putra yang terdapat pada kumpulan naskah dengan kode A, B, C, D, E, F, dan G. Penanda bahwa Serat Wulang Putra ini ditulis dan dikarang oleh PB IX tampak pada pupuh 5 , bait 1 atau bait 32 dari keseluruhan bait kumpulan naskah A.

Pan pinardi wuwuhing panganggit/ mring nak rabi tutuging ruwiya/ supaya têmbé wuriné/ tumrapa dadi tutur/marang ahli kang sêdya éling/ ngéling-éling wêwulang / amung lowung-lowung / kinarya anyandhêt driya/ driya arda kang tan wrin tata utami/ yèku mangka pusara//

Artinya:

Gubahan ini ditujukan/ kepada anak istri untuk melanjutkan cerita/ supaya kelak di kemudian hari/ dapat digunakan sebagai pelajaran/ untuk mereka yang ingin mengingat-ingat petuah orang tua yang berguna/ hal ini dapat digunakan sebagai pengikat hati/ khususnya hati yang tidak mengetahui tata hidup yang utama/ padahal hal itu merupakan hal yang menjadi pengikat//

Pada bait di atas dinyatakan gubahan karya ditujukan kepada anak istri untuk melanjutkan cerita supaya kelak kemudian hari dapat digunakan sebagai pelajaran untuk mereka yang ingin mengingat-ingat petuah orang tua yang berguna.

Teks tersebut kemudian ditata kembali oleh penulis keraton dengan memberi manggala dan kolofon. Kemudian diteruskan dalam Wulang Dalem PB IX kumpulan naskah PBA 59 (pupuh 1, bait 1) tampak manggala teks yang berisi pernyataan yang mengagungkan raja seperti di bawah ini:

Kinanthi pinurwèng kidung/Srinaréndra kang mandhiri/ Surakarta Kaping Sanga/ puwara widagdèng kawi/ wasis ing gêndhing wus kondhang/ mumpuni kidung palupi//

Artinya:

Tembang Kinanthi pembuka kidung/ Sri Raja yang berkuasa/ di Surakarta ke-9/ yang unggul dalam bersastra/ 
terkenal terampil dalam memainkan gamelan/ mumpuni dalam menulis kidung//

Berdasarkan teks di atas tampak bahwa terdapat tokoh penulis keraton yang menuliskan kembali karya PB IX. Sementara itu, karya PB IX yang merupakan hasil karya PB IX tampak pada diksi kalimat yang terdapat pada teks B pupuh 1, bait 2 di bawah ini:

Mêmalad waluyaning kung/ mangripta kidung sêsingir/ ngulari lêjaring driya/ driyarda angêmu wingit/ mangun wudharing duhkita/ tumuntur karsaning Widdhil/

Artinya:

Memohon agar diberikan kebahagiaan/ menciptakan kidung sisingir/ mencari obat kesedihan hati/ saat hati terasa sedih/ berusaha keluar dari kesedihan/ pasrah dengan kehendak Tuhan//

Adapun peran PB IX sebagai penganggit atau pengarang sekaligus penulis tampak pada teks B pupuh 1, bait 2 sampai dengan pupuh 6 , bait 13 . Pernyataan ini dikuatkan dengan adanya pernyataan dalam teks yang menyebutkan pada teks B pupuh 1, bait 2 bahwa penulis menciptakan kidung sesingir untuk mencari obat kesedihan hati. Saat hati terasa sedih kemudian berusaha keluar dari kesedihan lalu pasrah kepada Tuhan. Isi teks ini dapat dimaknai bahwa kesedihan penulis yang teramat hebat, sehingga berusaha menghibur diri dengan menuliskan karya sastra. Apabila dikaitkan dengan keadaan, PB IX mengalami kesedihan yang sangat hebat ketika permaisuri yang sangat dikasihinya yaitu Ratu Pakubuwana me- ninggal pada tahun 1887 .

Pada waktu itu, usia PB IX 56 tahun, sehingga keadaan ini tampak digambarkan dari teks E pupuh 5, bait 12 Serat Wulang Dalem PB IX yang tersimpan di Sonobudoyo dengan kode PBA 59 yang kemudian menyatakan bahwa penulis hanya bisa memohon agar dapat hidup bahagia dan panjang umur, hati yang terang dan mata yang awas, terampil dalam melakukan berbagai hal, pantas apabila berbusana agung serta tidak terganggu oleh siapapun dalam melaksanakan kehendaknya, seperti pada kutipan berikut ini:

Mung mukti lan panjang yuswa/ katularan kang nganggit/ padhanging driya trus nétra/ wasising sabarang kardi / pantês yèn busana di/ dinulur sakajatipun/ tumuntura mring wayah/ amung ingkang saprakawis/ kang mangripta nyuwun pamit sugih garwa//

\section{Artinya:}

Penulis hanya memohon agar dapat hidup bahagia dan panjang umur/ hati yang terang dan mata yang awas/ terampil dalam melakukan berbagai hal/ pantas apabila berbusana agung/ serta tidak terganggu oleh siapapun dalam melaksanakan kehendaknya/ semua itu menurun kepada cucu/ hanya satu hal/ yang tidak dapat dilaksanakan oleh penulis yaitu beristri banyak//

Dalam biografi PB IX diceritakan bahwa sejak muda PB IX memang sangat suka memantaskan diri dengan memakai busana yang dikreasikan sendiri walaupun berbahan sederhana sehingga hal itu ditiru oleh banyak pangeran pada waktu itu (Para Wayah Dalem, 1952: 17).

Untuk mencari data tentang biografi 
PB IX dilakukan pula dengan wawancara mendalam, disebutkan oleh informan bernama Ahmad Syarifuddin yang menyatakan bahwa PB IX adalah seorang yang gemar ilmu mursid dan mempunyai guru bernama Mbah Kahar (catatan lapangan IV). Dalam teks Wulang Dalem PB IX yang tersimpan di Museum Sonobudoyo kode PBA 59 (naskah E) disebutkan pula nama Ngabdulkahar. Penulis menyebut sedang mengingat-ingat pelajaran dari Ngabdulkahar yang sudah membimbing dengan telaten dan mengajar dengan kuat, seperti pada kutipan teks $F$ pupuh 8 , bait 1 berikut ini:

Kasmaran ingsun Karasèng yèn éling / wêwulangé guruningwang/ Ngabdulkahar wis mangruwèng/ alim talatèn yèn mulang/ kuwat umuré dawa / nora sah ngibadahipun/ suprandènê sugih garwa//

\section{Artinya:}

Terasa di dalam hati apabila ingat/ tentang pelajaran guruku/ Ngabdulkahar yang sudah membimbing/ alim telaten saat mengajar/ kuat dan berumur panjang/ tekun beribadah/ namun demikian banyak istri/

Oleh karena itu, penulis teks tersebut dapat disebutkan adalah PB IX.

Selanjutnya, pada kumpulan naskah A, B, C, dan D pada bagian Serat Wulang Wanita pada pupuh 36 , bait 14 seperti pada kutipan berikut:

Kang masastha Kunthara warsa Lip / sêngkala rinaos/ kawilêt ing kawi wangsalanél Yitmèng Praja Cipta kang kawijil/ Kangjêng Sribupati/ karsa amanawung//

Artinya:
Windu Kunthara tahun Alip/ sengkala berbunyi/ pan winangsit kawi sengkalannya / yitmèng praja cipta kang kawijil yang disampaikan/ Kangjêng Sri Bupati/ berkenan mengarang//

Terdapat penanda bahwa PB IX memberikan pokok-pokok pikiran untuk karangannya yang kemudian dituliskan oleh penulis keraton. Pada serat tersebut dituliskan oleh penulis keraton bahwa mulailah raja memberi pesan kepada seluruh wanita yang bersuami agar patuh kepada kehendak suami, memahami, dan menyenangkan hati suami, tampil dengan raut muka yang menyenangkan karena itu dapat menumbuhkan cinta seperti pada kutipan berikut:

Murwèng karsa Sang Nata sung wangsit/ mring sagunging wanita kang samya/ winêngku marang priyanél kudu manut sakayun/ ngayam-ayam karsaning laki/ lêlèjêm mamrih rêna/ karanané iku/ dadi jalaraning trêsna/ ning wong priya yayah guna lawan dhêsthi/ pasthiné mung élingan// (teks A pupuh 33, bait 1)

Artinya:

Mulailah raja memberi pesan/ kepada seluruh wanita/ yang bersuami/ harus patuh kepada kehendak suami/ memahami dan menyenangkan hati suami/ tampil dengan raut muka yang menyenangkan/ karena itu/ dapat menumbuhkan cinta/ hal itu harus selalu diingat//

Pada penulisan Serat Wulang Wanita ini diksi yang dipergunakan tidak sama dengan diksi yang dipergunakan untuk menulis dan mengarang PB IX. Apabila dalam penulisan serat yang dikarang dan 
ditulis oleh PB IX sering menggunakan kata ganti orang pertama dan kedua, maka dalam Serat Wulang Wanita ini penulis tidak menggunakannya. Penulis langsung menuliskan hal-hal yang boleh dilakukan dan tidak boleh dilakukan oleh wanita.

Peran PB IX sebagai pengarang pokokpokok pikiran tentang piwulang wanita juga terdapat pada kumpulan naskah A. Pokok-pokok pikiran secara jelas dituliskan seperti suatu tulisan yang sudah jelas pointer-pointer yang harus dituliskan.

PB IX sebagai pengarang dan penulis tampak pada karyanya yang berjudul Wararatna, bagian dari naskah A dan $\mathrm{C}$ pada pupuh 39 , bait 8,9 , dan bait 16 dituliskan bahwa PB IX menyebut putrinya dengan putri yang dipilih untuk tokoh dalam wejangannya, seperti kutipan di bawah ini:

Dhuh sutèngsun/ rungunên manira wuruk/ kabèh kang tinitah/ éndyah rèhning sira èstri/ mung sun kaya sanépa wêwulangingwang//

Cêkakipun/ supaya énggal dhinapur/ nini putraningwang/ èstokêna basa gati/ basa wadon/ iku wadi têgêsira// (teks A, pupuh 39, bait 8-9)

Artinya:

Wahai anakku/ dengarkan ajaran$\mathrm{ku} /$ semua yang ditakdirkan/ hanya engkau yang dipilih sebagai contoh wejanganku ini/ karena engkau seorang wanita//

Singkatnya/ agar gubahan ini segera selesai/ wahai putriku/ camkan katakata ini/ bahasa wanita/ itu artinya rahasia//

Dhuh sutèngsun/ iyêku sanêpanipun/ sasmita kang nyata/ ngong cêkak wêwulang iki/ dèn èstokna rasaning srat Wararatna / (teks A pupuh 39, bait 16)

Artinya:

Wahai anakku/ demikianlah ibaratnya/ perlambang yang nyata/ nasihat pendekku ini/ laksanakan isi dari Serat Wararatna//

Pada Serat Gandrung Turida yang merupakan bagian dari kumpulan naskah A, B, dan C tampak jelas peran PB IX sebagai penulis dan pengarang. Hal ini tampak pada teks A pupuh 40, bait 3 . Penyebutan kepada permaisuri Pakubuwana yang telah wafat, dengan menyatakan bahwa PB IX tidak akan menyusul ke akhirat karena di dunia masih banyak pekerjaan untuk menjaga anak cucu dan manusia seisi negara yang tentu tidak akan rela bila raja menyusul ke akhirat, seperti pada kutipan berikut ini:

Dhuh woting tyas ingsun wong akuning/ ingsun nora nusul mring dêlahan/ nêng jagat akèh gawéné/ prêlu ngrêksa nak-putu/ lan mênungsa isining nagri/ kabèh tan nana rila/ mungguh awakingsun/ yèn sumusula mring sira/ apan lagi nglakoni karsaning Widdhil payo padha séwangan//

Artinya:

Wahai kekasih hatiku/ hamba mengatakan hamba tidak akan menyusul di akhirat/ di dunia banyak pekerjaan/ untuk menjaga anak cucu/dan manusia seisi negara/ semua tidak ada yang rela/ jika saya menyusulmu ke akhirat/ karena sedang menjalankan kehendak Tuhan/ marilah kita berpisah//

Selanjutnya, pada teks A pupuh 40, bait 5 menyatakan bahwa PB IX sangat sedih 
ditinggalkan permaisuri dan tidak tahan ditinggal seperti pada kutipan berikut ini: Aywa mamang driyanira yayi / lamun ingsun tan èngêt mring sira/ ananging mêngko kapriyél dhawuhé Kangjêng Rasul/ sarupané alul-amrihi/ kudu têtêping iman/ marmané riningsun/ pakéwuh têmên wakingwang / ninggal sira tan bêtah manawung kingkin/ tan arsa dhahar néndra//

\section{Artinya:}

Jangan khawatir hatimu adinda/ jika suatu saat aku tidak ingat kepada engkau/ namun bagaimana/ perintah Kanjeng Rasul/ semua alul amrihi/ harus mempunyai tetap iman/ disebabkan adinda sedih sekali hamba meninggalkan engkau/ tidak tahan berpisah dengan dikau/ tidak ingin makan dan tidur//

Pada teks A pupuh 40, bait 6 dinyatakan bahwa PB IX sangat rindu, sehingga badan terasa lesu tanpa bisa melakukan pekerjaan. Rakyat melihat kesedihan rajanya sehingga turut sedih. Kesedihan PB IX yang menandakan bahwa teks tersebut adalah karangan dan tulisan raja tampak pada kutipan teks A pupuh 39, bait 7-8 di bawah ini:

Yên kêtlanjur goningsun mong kingkin/ lêsu lupa rasaning sarira/ tan bisa anglawan ing rèh/ing praja têmah kusut/ kasatmata nora prayogi/ tis-tis atining wadya/ yèn mulat sun gandrung/ andrênging tyas ingsun iya/ nêmbadani karêpé wong sanagari/ ri-ari misih branta//

\section{Artinya:}

Jika terlanjur hambamu menjaga rasa rindu/ badan terasa lesu/ tanpa bisa melakukan pekerjaan/ di kerajaan menjadi ruwet/ terlihat tidak baik/ hati para rakyat cemas/ jika melihat aku merindu/ keinginan hati yang kuat untuk bertemu denganmu/ untuk mengikuti keinginan orang senegara/ setiap hari masih sedih//

Teks ini ditulis oleh PB IX di masa usia PB IX sudah tua, hal ini tampak pada teks A pupuh 41, bait 1 yang menyatakan $\mathrm{PB}$ IX sudah menjadi kakek. Oleh karena itu, sulit menghilangkan kesedihan ditinggal permaisuri.

Yèn ta misiha taruna / iya awakingsun iki/gampang pamudharing rimang/ing mêngko wis kaki-kaki/ kangèlan lamun murih/ wudharé dhuhkitaningsun/susahé tumpa-tumpa/ jalaran akè pinikir/ karkating tyas mrih lêstari aywa cuwa//

Artinya:

Jika masih muda/ hambamu ini/ mudah menghilangkan kesedihan/ namun sekarang sudah menjadi kakekkakek/ sukar membuang kesedihan/ kesedihan sangat besar/ karena banyak pikiran/ maksud hati agar tetap lestari tidak kecewa//

\section{PB IX sebagai Pengayom}

Berdasarkan hasil penelitian terhadap serat-serat wulang $P B I X$, tampak posisi $\mathrm{PB}$ IX sebagai pengayom penulisan. Posisi tersebut memang merupakan suatu tata cara yang khas pada zamannya terutama pada zaman Kerajaan Surakarta. Sebagai pengayom penulisan karya-karya sastra, sering memuat nama-nama penyair atau penulis lain dalam karya sastranya. Di bawah ini tabel teks dan penanda teks peran PB IX sebagai pengayom. 
Tabel 18. Peran PB IX sebagai Pengayom

\begin{tabular}{|c|c|c|c|}
\hline No. & Indikator & Serat & Ket \\
\hline 1. & $\begin{array}{l}\text { Mengakhiri tembang Gambuh/ ini karena Adisara } \\
\text { disela oleh kantuk/ akan disambung besuk apabila } \\
\text { hambamu sudah mulai bangun/ }\end{array}$ & Wulang Rajaputra & $\begin{array}{l}\text { Teks A, p. } 17, \text { b. } 9 \\
\text { Teks B, p. } 21, \text { b. } 9 \\
\text { Teks D, p. } 24, \text { b. } 9 \\
\text { Teks E, p. } 14, \text { b. } 9\end{array}$ \\
\hline 2. & $\begin{array}{l}\text { Pada waktu tidur tiba-tiba terbangun/ Adisara } \\
\text { memulai lagi dengan memasukkan ujung pena ke } \\
\text { tinta/ kemudian mengambil kertasnya/ berkeinginan } \\
\text { untuk melanjutkan lagi/ }\end{array}$ & Wulang Rajaputra & $\begin{array}{l}\text { Teks A, p. } 18, \text { b. } 1 \\
\text { Teks B, p. } 22, \text { b. } 1 \\
\text { Teks D, p. } 25, \text { b. } 1 \\
\text { Teks E, p. } 15, \text { b. } 1\end{array}$ \\
\hline 3. & $\begin{array}{l}\text { Hamba benar-benar menghaturkan/ wejangan dari Ki } \\
\text { Nursiddhi/ secara urut/ tepat dan beraturan/ yang } \\
\text { dapat dipakai untuk teladan bagi raja// }\end{array}$ & Wulang Rajaputra & $\begin{array}{l}\text { Teks A, p. } 24, \text { b. } 1 \\
\text { Teks B, p. } 29, \text { b. } 1 \\
\text { Teks D, p. } 32, \text { b. } 1 \\
\text { Teks E, p.22, b. } 1\end{array}$ \\
\hline 4. & $\begin{array}{l}\text { Mulailah Raja memberi pesan/ kepada seluruh } \\
\text { wanita/ yang bersuami/ harus patuh kepada } \\
\text { kehendak suami/ }\end{array}$ & Wulang Wanita & $\begin{array}{l}\text { Teks A, p. } 33, \text { b. } 1 \\
\text { Teks B, p. } 38, \text { b. } 1 \\
\text { Teks D, p.35, b. } 1\end{array}$ \\
\hline 5. & $\begin{array}{l}\text { Windu Kunthara tahun Alip/ sengkala berbunyi/ pan } \\
\text { winangsit kawi sengkalannya/ yitmèng praja cipta kang } \\
\text { kawijil yang disampaikan/ Kangjêng Sri Bupati/ } \\
\text { berkenan mengarang// }\end{array}$ & Wulang Wanita & $\begin{array}{l}\text { Teks A, p. } 36, \text { b. } 14 \\
\text { Teks B, p. } 41, \text { b. } 14 \\
\text { Teks D, p. } 38, \text { b. } 14\end{array}$ \\
\hline 6. & $\begin{array}{l}\text { Lakukan tugas tugas siapa yang menulis/ mengutip } \\
\text { karangan dengan kesabaran/ dan semua keinginan/ } \\
\text { supaya tertata untuk dihaturkan/ Sang Raja// }\end{array}$ & Wewarah & Teks A, p.1, b.5 \\
\hline 7. & $\begin{array}{l}\text { Setelah selesai dalam menulis laporkanlah kepada/ku } \\
\text { dan/ melaporkan selesainya pembuatan/ Sana-Sunu } \\
\text { alap-alap// }\end{array}$ & Wewarah & Teks A, p.1, b.24 \\
\hline
\end{tabular}

Pada Serat Wulang Raja Putra tertulis nama Adisara. Dimungkinkan Adisara adalah penulis teks tersebut. Penulisan teks tersebut dalam rangka menjalankan tugas dari raja. Adapun data adanya nama Adisara sebagai penulis pada Serat Wulang Raja Putra yang terdapat pada naskah A, $\mathrm{B}$, dan $\mathrm{C}$ pada akhir penulisan pupuh 13 , bait 5 tertulis kutipan seperti berikut ini:

Lir anggané wong supêna/ angantuk sinambi nulis/Sabtu Lêgi ping sakawan / Kasanga Rabinguakir/ Jimakir Windu Adi/ Mandhangkungan ing jam pitu/ sangkala Luhurira/ Sang Brahmana Nara- pati/ dipunagung aksama pun Adisara / /

Artinya:

Tubuh penulis seperti halnya tubuh orang yang sedang bermimpi/ Walaupun mengantuk namun tetap menulis/ pada Sabtu Legi tanggal empat/ Musim kesembilan bulan Rabingulakir/ Jimakir Windu Adi/ Mandhangkungan pada jam tujuh/ dengan sengkala tahun Luhurira/ Sang Brahmana Narapati yaitu 1810 / berikanlah maaf yang sebesar-besarnya kepada Adisara// (p.13, b.5) 
Adapun pada naskah E dengan kode PBA 59 yang tersimpan di Sonobudoyo, pada pupuh 13, bait 5 di situ tertulis:

Lir anggané wong supêna/ angantuk sinambi nulis/ Sabtu Lêgi ping sakawan/ Kasanga Rabingulakir/ Jimakir Windu Adi/ Mandhangkungan ing jam pitu/ sangkala Luhurira/ Sang Brahmana Narapati/ dipunagung aksama pun Adisara//

\section{Artinya:}

Tubuh penulis seperti halnya tubuh orang yang sedang bermimpi/ Walaupun mengantuk namun tetap menulis/ pada Sabtu Legi tanggal empat/ Musim kesembilan bulan Rabingulakir/ Jimakir Windu Adi/ Mandhangkungan pada jam tujuh/ dengan sengkala tahun Luhurira/ Sang Brahmana Narapati yaitu 1810/ berikanlah maaf yang sebesarbesarnya kepada Adisara//

Pupuh tersebut dilanjutkan dengan tembang Gambuh, akhir pupuh tersebut juga terdapat penulisan nama Adisara, seperti kutipan di bawah ini:

Pinunggêl têmbang Gambuh/Adisara anyêlani ngantuk/ sinambungan bénjang ulun yèn wus nglilir/ kèndêl sangkalaning taun/ Luhur Sang Sarira Katong //

Artinya:

Mengakhiri tembang Gambuh/ ini karena Adisara disela oleh kantuk/ akan disambung besuk apabila hambamu sudah mulai bangun/ beristirahat untuk mencari angka tahun/ Luhur Sang Sarira Katong yaitu 1810//

Selanjutnya, pupuh Gambuh tersebut sambung menyambung dengan pupuh
Kinanthi, pada permulaan penulisan pupuh tersebut terdapat teks yang menunjukkan Adisara adalah penulis. Adapun kutipan pupuh ini adalah seperti di bawah ini:

Ngaliliré saking turu/ Adisara dulit mangsi/ anganthi daluwangira/ sêdya dugèkakên malih/ aturé anglir supêna/ ngênani tyasé Sang Pêkik//

Artinya:

Pada waktu tidur tiba-tiba terbangun/ Adisara memulai lagi dengan memasukkan ujung pena ke tinta/ kemudian mengambil kertasnya/ berkeinginan untuk melanjutkan lagi/ pembicaraannya sangat tenang seperti orang bermimpi/ sehingga mengenai hati Sang Pekik//

Adapun data adanya nama Adisara sebagai penulis yang terdapat pada teks Wulang Dalem PB IX, yaitu manuskrip yang tersimpan di perpustakaan Sonobudoyo dengan kode PBA 59 terdapat pada teks E pupuh 13, bait 5, pada akhir penulisan pupuh ke-13 Sinom, tertulis:

Kasmaran jroning ngaguling/Adisara supênanya/ panggih kaki-kaki kêmpong/ sarwa langking busananya/ Nursidhi aranira/ mangkono wawarahipun/ dhuh ta gêndhuk aywa kêmba//

Artinya:

Jatuh cinta pada waktu tidur/ Adisara bermimpi/ bertemu dengan lelaki tua yang kempot/ busananya serba hitam/ Nursidhi namanya/ demikianlah wejangannya/ duh anakku jangan berputus asa//

Akhir penulisan teks oleh Adisara tam- 
pak pada penulisan teks E di pupuh 21 Dhandhanggula bait 1 seperti tampak pada kutipan di bawah ini:

Titi tamat manitrèng kintaki/ sêsêndhon ulun pun Adisara / nèng Langênarja dunungél ri Soma Pon anuju/ tabah astha ping nêm sitèngsi/ Ngijroil sangatira/ Maktal wukunipun/ Rabiakir adi nujwa/ ing Jimakir luhur Sang Sarira Aji/ muji ring karaharjan/

\section{Artinya:}

Telah tamat penulisan surat/ senandung dari hamba Adisara/ yang berada di Langenarja/ pada hari Senin Pon/ jam delapan, tanggal enam/ bulan saat Ngijroil/ wuku Maktal/ Rabingulakir Adi/ Windu Jimakir dengan sengkala tahun Luhur Sang Sarira Aji/ semoga mendapat kemakmuran//

Peran PB IX sebagai pengayom juga tampak pada Serat Wewarah hal itu tampak pada pupuh 1 bait 1 kumpulan naskah A seperti kutipan di bawah ini:

Wiyata di/ anggit Dalêm/ Jêng Srinata//

Artinya:

Ajaran agung/ karya/ Susuhunan//

Dalam Serat Wewarah tidak ditemukan nama penulis. Dalam teks hanya disebutkan bahwa setelah ditulis semua diserahkan pada raja.

Peran Pakubuwana IX sebagai pengayom juga tampak pada Serat Jayeng Sastra yang terdapat pada kumpulan naskah B dan C seperti pada kutipan berikut ini:

Palastrèng cinitra wus/ kagungan dalêm ingkang Sinuhun/ Pakubuwana kaping Sanga marêngi/ linuri-luri kang luhur/
Surakarta angadhaton// (teks B, pupuh 18 , bait $18 \&$ teks D, pupuh 21 , bait 18 )

Artinya:

Sudah larut di dalam gambaran/ Kagungan Dalêm Ingkang Sinuhun/ Pakubuwana ke Sembilan/ dalam rangka memberi nasihat yang luhur/ yang berkedudukan di Surakarta//

Pada teks tersebut tidak tampak penulis serat itu. Pada akhir baris tampak bahwa penulisan teks dipersembahkan untuk $\mathrm{PB}$ IX.

\section{KESIMPULAN}

Sistem kepengarangan pada serat-serat wulang menunjukkan pola-pola istanasentris dalam kajian terhadap sistem kepengarangan serat-serat wulang PB IX yang berjumlah 8 naskah, maka tampak adanya pola-pola sistem kepengarangan sebagai seorang pengarang dan penulis. $\mathrm{PB}$ IX sebagai pengarang dan penulis, tampak pada gaya tuturan dalam teks yang menyebut sebutan adikku, guruku Ngabdul Kahar, guruningwang, trahingwang, anak$\mathrm{ku}$, woting tyasingsun, dan sutengsun. Gaya tuturan tersebut, terdapat pada gaya tuturan dalam Serat Wulang Dalem Kaping IX, Serat Darmarini, Serat Wulang Putra, Serat Jayengsastra, serta Serat Gandrung Turida.

Selanjutnya, peran PB IX sebagai pengayom tampak pada karya-karya berjudul Wulang Raja Putra, Wulang Wanita, dan Wewarah. Peran PB IX sebagai pengayom disamping menjadi pengayom penulisan atau yang memerintahkan agar karya sastra ditulis, kadang-kadang ikut ambil bagian dalam penciptaan kerangka karangan. 


\section{DAFTAR PUSTAKA}

Baroroh-Baried, Siti, Siti Chamamah Soeratno, Sawoe, Sulastin Sutrisno, dan Moh. Syakir. 1985. Pengantar Teori Filologi. Jakarta: Pusat Pembinaan dan Pengembangan Bahasa Departemen Pendidikan dan Kebudayaan.

Behrend, T.E. 1993. "Manuscript Production in Nineteenth-Century Java: Codicology and the writing of Javanese literary history", dalam Bijdragen tot de Taal-, Landen Volkenkunde Journal of the Humanities and Social of Southeast Asia.

1997. Katalog Induk NaskahNaskah Nusantara Jilid 3-B Fakultas Sastra Universitas Indonesia. Jakarta: Yayasan Obor Indonesia.

Darusuprapta. 1984. "Beberapa Masalah Kebahasaan dalam Penelitian Naskah", Widyaparwa. No. 26 Oktober. 1-2. Yogyakarta: Balai Penelitian Balai Bahasa.

Dharwadker, Vinay. 2003. "The Historical Formation of Indian-English Literature" dalam Sheldon Pollock (ed.), Literary Cultures in History Recons- tructions from South Asia. London: University Of California Press.

Florida, Nancy K. 2000. Javanese Literature in Surakarta Manuscripts Volume II Manuscripts of The Mangkunegaran Palace. New York: Southeast Asia Program Cornell University.

Girardet, Nikolaus, Suzan Piper, dan R. M Soetanto. 1983. Descriptive Catalogue of the Javanese Manuscripts and Printed Books in the Main Libraries of Surakarta and Yogyakarta. Weisbaden: Franz Steiner Verlag GMBH.

Margana, S. 2004. Pujangga Jawa dan BayangBayang Kolonial. Yogyakarta: Pustaka Pelajar. 2003. Kraton Surakarta \& Yogyakarta 1769-187. Yogyakarta: Pustaka Pelajar.

Saktimulya, Sri Ratna. 2016. Naskah-Naskah Skriptorium Pakualaman: Periode Paku Alam II (1830-1858). Jakarta: Kepustakaan Populer Gramedia.

Wahjono, Parwatri. 2004. "Sastra Wulang dari Abad XIX: Serat Candrarini Suatu Kajian Budaya", Jurnal Makara, Sosial Humaniora, Vol. 8. No. 2, Agustus 2004. 